\title{
Percepción de estudiantes universitarios sobre algunos aspectos de su construcción social genérica
}

\section{RESUMEN}

El artículo presenta percepciones que tienen estudiantes universitarios varones y mujeres acerca de prácticas genéricas que asimilan como equitativas e inequitativas en su círculo primario de socialización; qué papeles genéricos se les asignaron en su familia y en los juegos de su infancia, teniendo en cuenta que las construcciones culturales, impuestas, binarias y convencionales influyen en la construcción de la identidad de género de los sujetos y sienta las bases de las normas de funcionamiento de la sociedad; sin embargo, se sustenta que éstas no son definitivas, pues como toda construcción, pueden cambiar. En esta lógica, se muestran conjuntamente las manifestaciones con las que estos sujetos han tomado distancia de lo que se les enseñó sobre cómo debería ser una mujer y cómo debería ser un hombre, acompañadas de sus reflexiones que intentan romper en el entorno cotidiano con relaciones de género desiguales y la posible transformación de prácticas inequitativas en favor de prácticas equitativas. El artículo forma parte de una investigación más amplia sobre percepciones de estudiantes universitarios respecto a la equidad de género. ${ }^{1}$

1 El artículo que se presenta es una adaptación y actualización del capítulo tres de la tesis que se presentó para obtener el grado de Maestra en Educación, la cual se tituló: "Percepción de estudiantes universitarios respecto a la equidad de género".

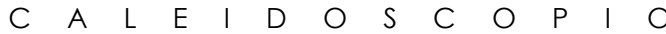


Palabras clave: sexo-género, equidad, construcción social, familias, juegos.

\section{ABSTRACT}

This article focuses on a chapter from the thesis "Perception of university students about gender equality". Its main objectives were to recover the answers provided by the students in order for them to end gender biased relationships in their daily lives, as well as to present theoretical elements that would incite reflections and a possible transformation of unequal practices in favor of gender equality.

\section{PLANTEAMIENTO DEL PROBLEMA Y PREGUNTA DE LA INVESTIGACIÓN}

El educar en equidad de género es tarea urgente; las necesidades sociales se han diversificado y han modificado formas de convivencia que hasta hace algunas décadas eran inamovibles. La educación tiene que ver con la formación de mujeres y hombres que puedan incorporarse a la sociedad y resolver problemas que se presentan en lo cotidiano. Actualmente los roles de género han ido cambiando; esta situación no ha permanecido ajena al sistema educativo y ha propiciado que el tema se coloque y se aborde como un asunto relevante en la formación de mejores seres humanos y, por ende, de una sociedad más incluyente e igualitaria, es decir más progresista.

La introducción de educación en género responde también a una serie de compromisos plasmados en diferentes documentos que México ha firmado y ratificado a nivel internacional, tales como la Convención sobre la Eliminación de todas las Formas de Discriminación contra la Mujer (CEDAW) y su Comité de Vigilancia 1979; y la Convención Interamericana para Prevenir, Sancionar y Erradicar la Violencia contra la Mujer (Convención Belém do Pará) 1994, cuyos contenidos han influido para la creación o modificación de leyes mexicanas como la propia Constitución Política Vigente de los Estados Unidos Mexicanos; la Ley General para la Igualdad entre Mujeres y Hombres 2006; la Ley General de Acceso de las Mujeres a una Vida Libre de Violencia 2007; y la Ley Federal para Prevenir y Eliminar la Discriminación 2003. 
Por su parte, el documento Objetivos de Desarrollo del Milenio de 2015 establece en su tercer punto: Promover la igualdad de género y el empoderamiento de la mujer, tomando en cuenta que si bien se puede hablar de algunos avances, es necesario trabajar mucho más en el tema puesto que la desigualdad de género está vigente:

Las mujeres siguen siendo objeto de discriminación para acceder al trabajo, a los bienes económicos y para participar en la toma de decisiones privadas y públicas... también tienen mayor probabilidad de vivir en la pobreza que los hombres. Globalmente, las mujeres ganan un 24\% menos que los hombres. En el $85 \%$ de los 92 países para los que se dispone de datos sobre las tasas de desempleo por nivel de educación para los años 2012 -2013, las mujeres con educación avanzada tienen tasas de desempleo mayores que los hombres con niveles de educación similar. A pesar del continuo progreso, en la actualidad el mundo todavía tiene un largo camino por delante en cuanto a la representación equitativa de los géneros en la toma de decisiones privadas y públicas. (Objetivos de Desarrollo del Milenio informe 2015).

Culturalmente, la sociedad mexicana dista mucho de tener prácticas equitativas; las mujeres siguen colocándose en situaciones de desventaja en el ejercicio de derechos fundamentales que tienen que ver con temas de educación, violencia, economía, alimentación, poder político, derechos sexuales y reproductivos, recreación, etc. Luego entonces, resulta primordial educar en género dentro y fuera de las aulas para poder construir una realidad social distinta; esta idea se vincula con la afirmación de que los seres humanos representamos la realidad de acuerdo a una construcción social que se va conformando genéricamente y que se puede transformar. En esa lógica se va institucionalizando y sedimentando un contexto que demarca ciertos cánones que se nos aparecen como naturales. Uno de los pilares teóricos que nos lleva a afirmar lo anterior se erige en "La construcción social de la realidad" (Berger y Luckmann, 1968), obra que desarrolla cómo es que quienes formamos la sociedad continuamos y consolidamos la edificación de costumbres, significados, saberes, etc. Berger y Luckmann hacen reflexionar en la premisa de que hay una realidad existente a priori a nuestro alcance, en la cual, nos apropiamos de una realidad dada que ha sido previamente habitualizada, institucionalizada y legitimada por quienes nos antecedieron en el mundo, que se perpetúa y permite que los significados subjetivos se den por hecho como realidades objetivas. Los seres humanos somos construidos por esta estructura social ya dada, pero a la vez somos sus constructores permanentes. 
Es pertinente retomar aportes de quienes ven en la pedagogía una herramienta para la transformación social; por ejemplo Paulo Freire, quien postuló que quien tiene en sus manos la tarea de educar tiene la responsabilidad de incidir activamente en la sociedad para transformarla; él planteó que los asuntos que tienen que ver con la educación no son solamente problemas pedagógicos; sino que tienen una índole política y ética como cualquier otro problema, como los financieros o los económicos, y la tarea primordial de quien pretende enseñar implica redibujar el mundo, repintarlo, rehacerlo, es decir, reconstruirlo.

Para lograr este fin es preciso plantear preguntas que propicien discusión, reflexión y profundización sobre aspectos relevantes en la manera en como nos relacionamos genéricamente; es por ello que vale la pena preguntar, ¿qué percepción tienen estudiantes universitarios acerca de las relaciones con equidad e inequidad de género y cómo responden ante estas situaciones? ${ }^{2}$

Investigar sobre cómo se construyen los roles genéricos y cómo se manifiestan en distintos ámbitos de la sociedad, así como el planteamiento de alternativas que apunten hacia la equidad de género ha sido materia de diversos estudios; el presente, pretende contribuir en la medida de lo posible a proporcionar algunas respuestas a preguntas que probablemente han estado ahí históricamente, interrogantes que quizás muchas personas nos hemos planteado no siempre encontrando una respuesta sino tal vez más preguntas, aspira a ser una voz entre quienes han brindado aportes teóricos para continuar en el estudio y profundización del tema, particularmente tomando en cuenta el aspecto educativo, familiar y los juegos, como lo han revisado ya algunos autores como Caldera en 1989, Subirats en 1988, Shaffer en 2000, Barberá en 2005, y Mosteiro en 2013, por mencionar algunos.

\section{METODOLOGÍA}

El razonamiento científico que guió este estudio fue el paradigma cualitativo. Durante este trabajo se alejó de pretender revelar verdades absolutas e inamovibles, puesto que los grupos que conforman la sociedad son complejos y dinámicos " $[$... l la sociedad se construye en

2 A fin de intentar responder esta pregunta, se elaboraron algunas otras más específicas que se presentan en el apartado de metodología. 
un contexto histórico social-determinado. La realidad social es producto de la acción de los hombres[... ] la realidad es inacabada, inconclusa; se va construyendo[... |". (Pérez en Serbia, 2007:125). Desde esta postura, sólo se intenta observar para interpretar en sus percepciones: "El investigador social intenta comprender a otros sujetos que se encuentran sujetados como él [...] se sitúa e interpreta un mundo social ya pre interpretado" (Serbia, 2008:127).

Los hallazgos de la investigación se expusieron de manera conjunta con sustentos teóricos, de tal manera que se presentan como un tejido que entrelaza ambos, lo que devino en categorías de estudio que se construyeron con base en leer y releer los resultados del trabajo de campo a fin de poder entenderlo, comprenderlo y presentarlo, y del cual hubo un apropiamiento a partir de un proceso individual de empoderamiento ${ }^{3}$ en el cual de manera personal hubo una sensación de capacidad de generar categorías propias, en apoyo en todo momento por la teoría de la construcción social de Berger y Luckman y de la teoría de género.

Se recogió la información por medio de entrevistas a profundidad, realizadas entre el 13 de mayo y el 5 de noviembre de 2009 y se utilizaron seudónimos para respetar el anonimato de quienes participaron para proteger su identidad. Las preguntas planteadas tuvieron como propósito precisamente conocer acerca de la formación genérica que se les proporcionó en su círculo de socialización primaria ${ }^{4}$ poniendo especial énfasis en los roles y estereotipos en tareas domésticas y en

El concepto de empoderamiento -o apoderamiento- tiene su origen en la educación popular de Paulo Freire y su desarrollo teórico está unido al análisis de género, fue acuñado en la Conferencia Mundial de las Mujeres en Beijing (Pekín) en 1995 para referirse al aumento de la participación de las mujeres en los procesos de toma de decisiones y acceso al poder. Actualmente, esta expresión conlleva también otra dimensión: la toma de conciencia del poder que individual y colectivamente ostentan las mujeres y que tiene que ver con la recuperación de la propia dignidad de las mujeres como personas.

4 En su clásico tratado sobre Sociología del Conocimiento, Peter Berger y Thomas Luckmann (1968) se refieren a la socialización primaria como el proceso previo de cualquier socialización, que tiene lugar en los primeros años de vida y en el que se forma un primer yo que se internaliza con el padre y la madre (o quienes fungen como tales), se crea un yo formado con anterioridad, un mundo ya internalizado, el cual pasa a convertirse de un yo individual a un yo social, en el que se interactúa con otros individuos (socialización secundaria) y ya no se ve a sí mismo como un ser aislado sino comprende que es un ser con los otros, es decir, un ser social. 
los juegos; ${ }^{5}$ las cuestiones se plantearon como una guía flexible y que se adaptó conforme iban variando las respuestas. Las preguntas base fueron: ¿En tu casa, se siguen papeles considerados culturalmente como masculinos o femeninos? ¿Cuáles? ¿Qué opinas al respecto? ¿Puedes platicarme si en la infancia realizabas juegos considerados culturalmente como de niña o de niño? ¿Te gustaba hacerlo? ¿Te hubiera gustado jugar a algo distinto?

\section{Aclaración sobre lenguaje incluyente}

A fin de agilizar la lectura de este texto y siguiendo lineamientos ortográficos y académicos, se utilizó esporádicamente el masculino genérico, por lo que no se pretende en momento alguno desconocer o minimizar los aportes feministas para utilizar el lenguaje incluyente e incluir a ambos géneros.

\section{PARTICIPANTES}

La inquietud de convocar a estudiantes universitarios a abordar el tema de género surgió a partir de la propia práctica docente, en la cual de manera empírica, se observaban situaciones en la convivencia al interior de las aulas que impulsaron a abordar el tema de manera científica. En 2009, después de haber cursado la maestría en Educación, se lanzó la convocatoria al taller: "Construyendo Relaciones Equitativas" en dos universidades de León, Guanajuato; el requisito para ingresar al taller apuntaba a que era indispensable estar estudiando una licenciatura o haberla terminado recientemente, por lo tanto, la población que se investigó se inserta en la educación formal de nivel superior. Comenzaron doce estudiantes -seis hombres y seis mujeres- y terminaron nueve -cinco mujeres y cuatro hombres-. Los estudiantes eran provenientes de dos universidades, una pública y una privada; por parte de la Universidad de Guanajuato asistieron cinco estudiantes de la licenciatura en Trabajo Social, y cuatro de la Universidad Iberoamericana León, provenientes de las licenciaturas en Educación, Comunicación, Psicología y Derecho. El taller duró 4 sesiones de 5 horas cada una y se abordaron distintos temas sobre

5 Se anexa el formato de la entrevista al presente. 
género, cumplió la importante función de ser grupo focal y al término se realizaron las entrevistas.

Conociéndoles más de cerca se pudo percatar de que había un mosaico común de pensamiento, en el que en mayor o menor grado compartían una o algunas de estas características:

- Interés en la educación por la paz y los derechos humanos.

- Conciencia y preocupación por problemáticas sociales.

- Actividad en alguna causa social y trabajo en pro de su transformación positiva.

- Acercamiento y/o conocimiento previo sobre la perspectiva de género e inquietud por aprender más sobre el tema.

En el siguiente cuadro, se presenta información de los participantes con la finalidad de presentar aspectos de su perfil sociodemográfico y aproximarnos a su contexto: 


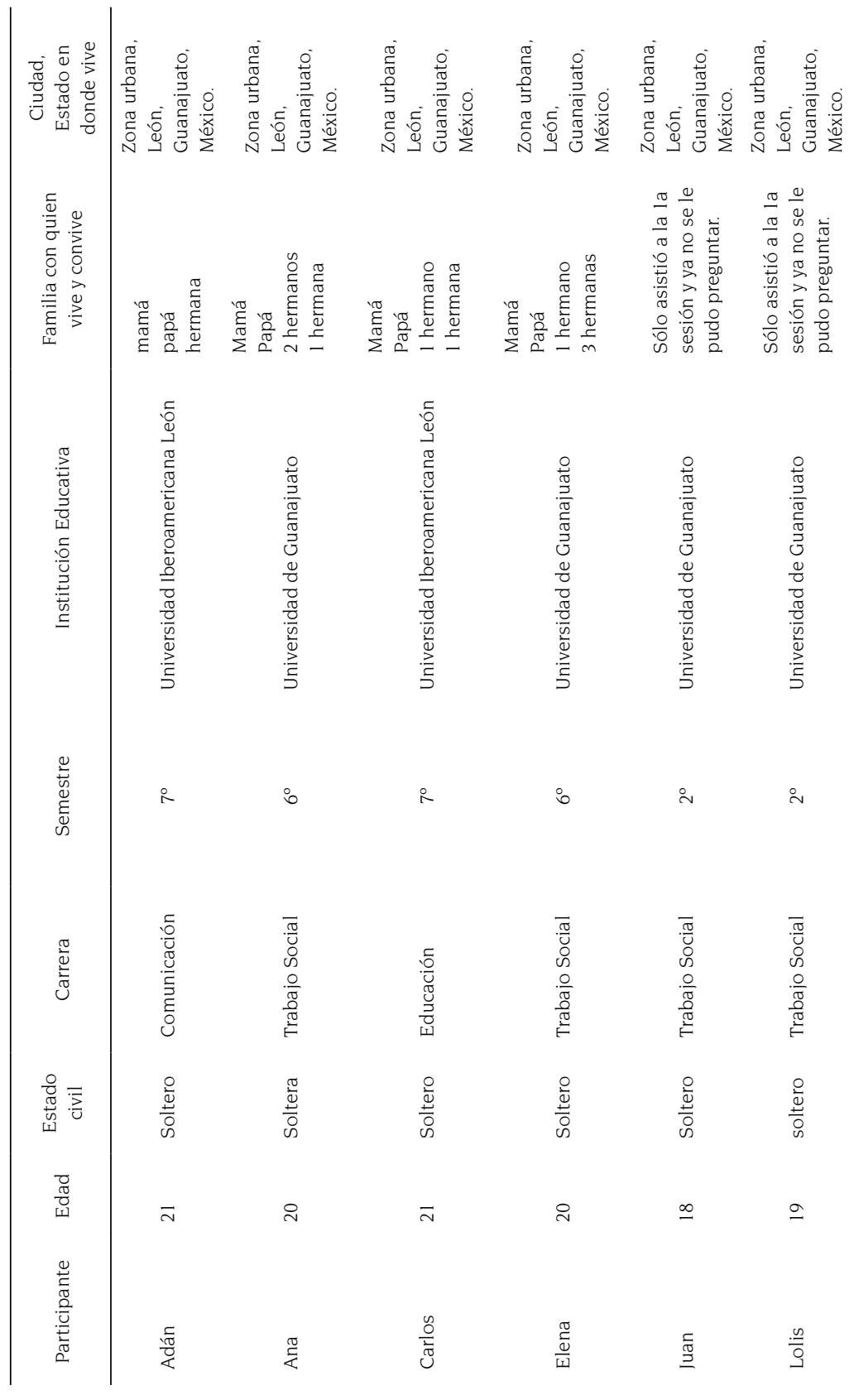




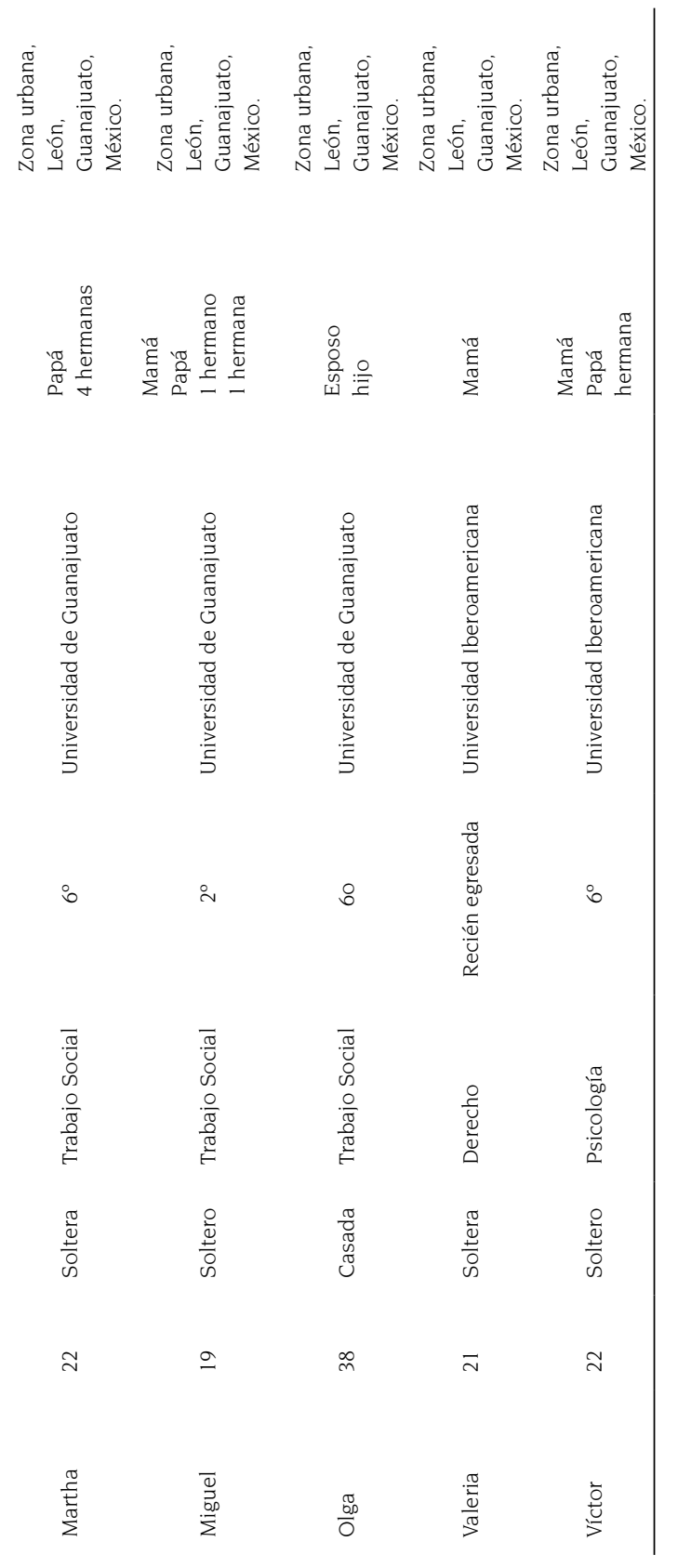

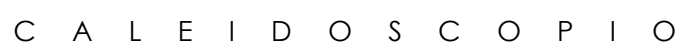


Si bien han pasado algunos años desde el comienzo de dicha investigación, se puede afirmar que el tema es vigente, ya que se vincula con el tema por medio de la propia formación académica y participación ahora en Aguascalientes, ciudad donde se han continuado los estudios en género y en el desempeño docente en cursos sobre equidad de género con estudiantes universitarios; ${ }^{6}$ ello ha permitido seguir observando; de igual manera, se ha podido notar que el contexto sociocultural entre León y Aguascalientes es similar, ya que ambos estados pertenecen al Bajío del país y comparten características comunes como la predominancia de ideologías conservadoras y la influencia del catolicismo tradicional en prácticas cotidianas, ya sea de índole privada o pública, lo cual permea en los modos en que se llevan a cabo las relaciones genéricas.

\section{APROXIMACIONES TEÓRICAS SOBRE LOS ESTUDIOS DE GÉNERO}

La teoría feminista ha logrado una profunda reflexión de la realidad entre los sexos, su análisis crítico de la realidad permitió que se repensaran y replantearan conceptos que se tomaban como realidades aprobadas, indiscutibles e inamovibles; uno de los aportes más importantes de la teoría feminista fue acuñar la categoría "género", que ha sido utilizada como una vital herramienta epistemológica que evidencia desigualdades históricas del binomio hombre-mujer y que propone nuevas formas de convivencia más diversas, incluyentes e igualitarias.

Desde los estudios de género, existen importantes aportes acerca de la distinción conceptual sexo-género. Simone de Beauvoir (1949) contribuyó con su libro El segundo sexo a repensar la identidad de las mujeres y la diferencia sexual haciendo un análisis crítico desde distintas disciplinas como la psicología, la historia, la antropología, la biología, etc., a lo que se entiende como "mujer" "No se nace mujer: llega una a serlo. Ningún destino biológico, físico o económico define la figura que reviste en el seno de la sociedad la hembra humana; la civilización es quien elabora ese producto" (Beauvoir, 1949:207). Esta filósofa francesa sentó bases fundamentales para comprender la construcción social del género, ya que social y culturalmente se forma a

6 He participado como instructora del curso intensivo "Súmate a la Equidad" en la Universidad Autónoma de Aguascalientes desde agosto de 2014 a la fecha. 
las mujeres -y, por lo tanto, también a los hombres- de una manera determinada, se les enseña a hablar, a caminar, a jugar, a comportarse como mujeres. En la década de los 70 se conceptualizó tal idea y a partir de entonces se utiliza como categoría de análisis desde los estudios de género y feministas.

La socióloga Ann Oakley (1972) explicó que las diferencias fisiológicas entre hombres y mujeres giran en torno al sexo, y corresponden al género las pautas de comportamiento culturalmente establecidas en el ámbito de lo femenino y lo masculino; pocos años después Gayle Rubin (1975), definió el sistema sexo-género como: "El sistema de relaciones sociales que transforma la sexualidad biológica en productos de actividad humana y en el que se encuentran las resultantes necesidades sexuales históricamente específicas". (Rubin, 1972:157).

El género, por tanto, es un constructo social, transmitido y regulado genérica e históricamente por una serie de reguladores sociales fundamentándose en diferencias meramente biológicas; entre estos reguladores sociales se encuentran las instituciones, los sistemas simbólicos, los patrones culturales, el lenguaje, los juegos, los papeles sociales, etc., los cuales influyen en el desarrollo y en la concepción del mundo de las personas.

Es imposible comprender adecuadamente qué es una institución, si no se comprende el hecho histórico en el que se produjo. Las instituciones, por el mero hecho de existir, también controlan el comportamiento humano estableciendo pautas definidas de antemano que lo canalizan en una dirección determinada. (Berger y Luckmann, 2005: 76)

Es precisamente en esta conjunción donde se pasa de la idea de construcción social de la realidad social a la de construcción sexo-género, afirmando que lo que se ha construido en torno al sexo-género obedece a patrones de comportamiento que no son acordes a la realidad actual y que son predominantemente patriarcales. La realidad social se construye a partir de significantes que se aprehenden socialmente, los cuales se asumen y apropian en cuanto son significativos para sí y para quien habita su mundo; es así como se internaliza el sistema sexo-género en esta zona que Berger y Luckmann llaman de socialización primaria, y que es "la primera por la que el individuo atraviesa en la niñez, por medio de ella se convierte en miembro de la sociedad" (Berger y Luckmann, 2005: 76). Esta realidad se perpe- 
túa generacional e históricamente sin cuestionar los razonamientos de los quehaceres cotidianos y las repercusiones que éstos tienen en términos de igualdad social: por ejemplo, a los niños les es permitido jugar con pistolas, pero no con muñecas, y viceversa.

El concepto patriarcado ha sido retomado y resignificado por el feminismo, y se explica en el constructo histórico teórico en el que se toma al hombre como referente y regente del sistema, ya sea de índole política, social, económica, cultural, educativa, etc.; en tal virtud, se obtiene un poder que permite, por el solo hecho de haber nacido hombre, de poseer y de ejercer prerrogativas especiales en una sociedad que deviene desigual en detrimento de las mujeres. Luz Maceira investigadora feminista de El Colegio de México explica que el patriarcado se puede entender actualmente como un:

[... sistema que se constituye en y mediante un sistema de prácticas reales y simbólicas que caracterizan a la sociedad y que alude a una forma de organización androcéntrica, sexista, en donde siguen existiendo la jerarquía y diversas formas del dominio material y simbólico en las distintas dimensiones del orden social $[\ldots \mid$ La organización es patriarcal cuando existe una organización de género y edad jerárquica y que prioriza los intereses de los hombres y mantiene sus privilegios en múltiples áreas de la vida social y política. (Maceira, 2008:241)

Algunas estudiosas internacionales del tema han sido Rosa Cobo en "Fundamentos del patriarcado moderno"; Gerda Lerner en "La creación del patriarcado", y Kate Millet en Política sexual", entre otras.

\section{ESTEREOTIPOS Y ROLES DE GÉNERO}

Los estereotipos son etiquetas, marcas, rubros con los que pretendemos describir a una persona y encasillarla en un genérico sin tomar en cuenta sus características particulares. Un estereotipo despoja a la persona de su individualidad y la somete a un común denominador calificándola desde la parcialidad; pueden usarse catalogando a alguien desde distintos ángulos, ya sea por su raza, por su edad, por su nacionalidad, por sus preferencias sexuales, por sus capacidades físicas, o precisamente por su género. (Romero, 2014: 106).

Desde la perspectiva de género, estas clasificaciones definen a una persona como masculina o femenina, las cuales se relacionan íntima- 
mente a roles de género que circunscriben a un binomio con atributos muy específicos y niega la diversidad; las personas actúan, sienten, son, desde una imposición social y no desde el anhelo propio.

Money (1955) estableció claramente su significado: "La expresión rol de género se usa para significar todas aquellas cosas que una persona dice o hace para revelar que él o ella tiene el estatus de niño u hombre, o niña o mujer, respectivamente". (Money, 1955:253). Entendidos de esta manera, los roles pueden significar ocupaciones, actividades, funciones, asignaciones, responsabilidades y también exenciones o prerrogativas que se generan en torno a una persona a partir de un dato biológico y casual, como haber nacido hombre o mujer. Éstos pueden convertirse incluso en exigencias sociales que conllevan una consecuencia si no se cumple, en nuestra sociedad puede ser el estigma social, el rechazo o la discriminación. Sin embargo, éstas no son características universales, ni estáticas, mucho menos otorgadas por la naturaleza, sino que son aprendidas y reproducidas respondiendo al contexto cultural; diversas culturas han demostrado que los roles o papeles de género son producto de la socialización a la que se expone cada persona; el trabajo de Mead con un pueblo de Nueva Guinea, por ejemplo, arroja sólida información al respecto:

Los arapesh moldean a cada niño nacido en el seno de su sociedad, de acuerdo con una aproximación de lo que ellos consideran que debe ser una personalidad humana normal. [...], consideran a hombres y mujeres como innatamente pacíficos, responsables y dispuestos a colaborar, capaces y deseosos de subordinar el yo a las necesidades de los que son más jóvenes o más débiles, derivándose de esta conducta una mayor satisfacción. Han envuelto con deleite esa parte de la paternidad que nosotros consideramos como específicamente maternal, ese minucioso y delicado cuidado del niño y la generosa satisfacción de verle progresar hacia la madurez. Mead (1935:159).

Al contrario de este ejemplo, los roles que tradicionalmente se han asignado a las mujeres son los relacionados a su condición reproductiva, las actividades que se realizan en espacio privado, la crianza, las labores domésticas, el cuidado de las personas y las relaciones familiares.

El papel de género se configura con el conjunto de normas y prescripciones que dictan la sociedad y la cultura sobre el comportamiento femenino o masculino. Aunque hay variantes de acuerdo con la cultura, la clase social, el grupo étnico y

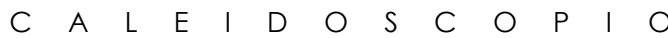


hasta el estrato generacional de las personas, se puede sostener una división básica que corresponde a la división sexual del trabajo más primitiva: las mujeres paren a los hijos y, por lo tanto, los cuidan: ergo, lo femenino es lo maternal, lo doméstico, contrapuesto con lo masculino, que se identifica con lo público. La dicotomía masculino-femenino, con sus variantes establece estereotipos, las más de las veces rígidos, que condicionan los papeles y limitan las potencialidades humanas de las personas al estimular o reprimir los comportamientos en función de su adecuación al género. Lamas (2008:33)

Tomando en cuenta las contribuciones teóricas expuestas, me parece oportuno presentar los resultados de la investigación a partir de este momento, de tal manera que se relaciona la información obtenida, conjuntamente con categorías del análisis teórico al tiempo que se discute e interpreta en un mismo acto.

\section{LAS FAMILIAS COMO PERPETUADORAS DE ROLES GENÉRICOS}

Se ubica el concepto de la socialización primaria (Berger y Luckmann 1968) para señalar que todas y todos los participantes tuvieron como plataforma común la institución familiar como su núcleo de socialización primaria. La mayoría de los participantes provienen de familias nucleares; ${ }^{7}$ sin embargo, se pudo deducir que al interior de estas familias existen matices; por lo tanto, se optó por clasificar a las familias nucleares atendiendo a la oscilación entre rigidez y flexibilidad entre unas y otras; a las primeras, es decir, a las que mantienen fijos los papeles de género preestablecidos se les dio el nombre de rígidas, y a las que han optado por la distribución de las tareas familiares se les denominó flexibles; la última es de tipo monoparental, conformada por el padre y sus tres hijas. En este caso, las preguntas detonantes para abrir la discusión relativa a su círculo familiar fueron: ¿En tu casa, se siguen papeles considerados socialmente como típicamente masculinos o femeninos? ¿Como cuáles?

$7 \quad$ Según UNICEF el hogar o gamilia nuclear: "Es el hogar particular integrado solamente por los cónyuges, los cónyuges con sus hijos, una persona con sus hijos, o una persona con sus padres". (UNICEF, 2003:88). 


\section{Familias nucleares rígidas}

Cinco de los participantes pertenecen a este tipo de familia, la educación que se transmite es rígida, tiene estructuras firmes en su organización y papeles comportamentales de género atendiendo predominantemente a su sexo. Miguel materializa esta idea entendiendo que en su familia lo marginan del grupo de mujeres y le dicen: tú eres aparte y nosotras aparte. En relación con las "familias nucleares rígidas" se pudo observar que se relacionaron al trabajo doméstico predominantemente femenino, al padre como proveedor principal, al padre considerado como máxima autoridad.

Se considera que el trabajo doméstico debe ser ejercido en mayor medida por las mujeres de la casa, independientemente de que tengan trabajo remunerado o no. En estas familias trabajan -o en algún momento han trabajado- hombres y mujeres de forma remunerada; sin embargo, los varones participan significativamente menos en labores domésticas y antes los varones no participaban:

Mi hermano lava los trastes dos veces a la semana, se encarga de ir a la tienda... los pequeños logros que se han conseguido respecto a las labores del hogar es porque mi hermana y yo hemos insistido en que se repartan las actividades de manera equitativa; sin embargo, no ha sido fácil, desde pequeñas la educación para nosotras fue diferente a la que se tiene con mis hermanos... (Ana, comunicación personal, 13 de mayo de 2009).

Principalmente, el padre provee y la madre se encarga de las labores domésticas. El dicho de Elena me hace pensar que por parte de ambos padres se define la idea de que el papá provee y la mamá se queda en casa:

Mi papá lo único que hace es trabajar, es el principal proveedor del hogar... mi mamá sigue pensando que el mantener la casa en orden es tarea de ella, y aunque hemos hecho algunos intentos de cambiar los roles, tanto mi papá como mi mamá no lo han permitido. (Elena, comunicación personal, 20 de mayo de 2009).

Por lo tanto, en esta familia, y tomando como referente el dicho de Elena, se deduce que el padre no participa en labores domésticas, su aportación es de tipo económica y también participa en tareas atribuidas al mundo masculino: 
Ya está como un patrón bien definido, el domingo mi papá y mi hermano se salen a lavar los carros, a cambiar el aceite... en el carro no participo, yo no sé si a lo mejor a mi carro le falta aceite, le falta agua, se los dejo a ellos, ellos cortan el pasto, los árboles y trabajan. (Elena, comunicación personal, 20 de mayo de 2009).

El padre tiene mayor peso en cuanto a autoridad y poder, no se aprecia una comunicación fluida con él. En general, reportaron tener mejor comunicación con su mamá que con su papá. Elena señala refiriéndose a la relación con su padre:

Tenemos muy mala comunicación... siempre llegamos a lo mismo. (Elena, comunicación personal, 20 de mayo de 2009).

La toma de decisiones es principalmente hecha por el padre, no hay acuerdos ni consensos. En este sentido, la autoridad paterna prevalece sobre la materna.

Mi papá y mi mamá no tienen una relación de extrema desigualdad, pero sí existe, no porque sean malas personas, sino porque así han vivido y han aprendido, y a pesar de que dialogan, se nota que quien toma decisiones y tiene un poder y un control económico, es el hombre (Adán, comunicación personal, 13 de mayo, 2009).

En la familia de Valeria definitivamente la autoridad máxima era su padre: de morra lo que decía mi hermano y mi papá tenía muchísimo más peso que lo que dijera mi mamá. (Valeria, comunicación personal, 7 de octubre de 2009).

Familias nucleares flexibles

Dos de los participantes pertenecen a este tipo de familias; aunque predominan los roles tradicionales, existe la intención y algunas acciones para modificarlos en la búsqueda de una convivencia más equitativa, quizás un elemento que ha influido para que se diversifiquen las tareas al interior de las familias es que ambos cónyuges tienen o tenían un trabajo remunerado.

En estas familias, las tareas domésticas se distribuyen. De lo dicho por este grupo de participantes se pudo deducir que cuando la pareja trabaja, las labores domésticas se reparten en mayor proporción entre los miembros de la familia; aunque sigue prevaleciendo la madre como principal responsable: 
Mi papá está acostumbrado a que le sirvan; se sienta y mi mamá automáticamente dice '¿Qué te voy a servir?'. A veces se da cuenta y nos quiere echar chamba... entonces sí se siguen, [los roles tradicionales] pero intentamos medio romper con algunos esquemas. [Da un ejemplo] Mi papá tiende a ayudar al quehacer, no se encasilla en que nada más la mujer, también nosotros tratamos de colaborar y decirle [a mi mamá] 'tú tranquila, tú dedícate a otras cosas'. (Carlos, comunicación personal, 20 de julio de 2009).

\section{Familia monoparental}

Con familia monoparental se referiere a la familia que está conformada por una jefa o un jefe de familia, quien lleva la responsabilidad de ser sostén moral, económico y del cuidado de las hijas e hijos en soltería.

Martha y sus dos hermanas fueron criadas por su papá únicamente; los roles en su familia no se diferenciaron significativamente. Las tareas son realizadas por cualquiera sin distinción de sexo; su papá se encargó de mantenerlas económicamente y realizar las tareas domésticas en los primeros años de su vida; desde pequeña participaba en quehaceres propios de su edad:

Yo no tengo mamá, entonces mi papá también a la cocina, a hacer quehaceres, en mi casa todas trabajamos, todas aportamos, no es así como que si eres mujer tú te dedicas a la casa y papá a trabajar... nos enseñó a no depender económicamente de alguien. (Martha, comunicación personal, 8 de agosto de 2009).

De lo anterior surgió la inquietud de saber si la ausencia de madre fue un hecho de peso para que la familia tuviera un desarrollo con características no tradicionales y las tareas fueran repartidas equitativamente

Yo creo que sí tuvo cierta influencia la falta de una figura materna, sin embargo, también podría creer que hay influencia al ser casi el 70\% o más mujeres dentro de la familia extensa de ambos padres... además no hay que olvidar que de familia somos cinco mujeres -contándome-y mi padre jeje...". (Martha, comunicación personal 8 de agosto de 2009).

Por otro lado, es posible pensar que la socialización en casa marca de alguna manera, pero no definitivamente porque, como se ha 
venido mencionando, esto puede cambiar; además debe adecuarse a las necesidades actuales, un participante perteneciente a una familia rígida hace un comentario crítico ante las reglas con las que lo criaron:

Las normas de antes entre ser hombre y ser mujer como que no... ya no tienen nada que ver con lo que estamos viviendo ahora. (Miguel, 14 de junio, 2009).

\section{LA INFLUENCIA DE LO LÚDICO EN LOS ROLES DE GÉNERO}

Otro aspecto que se tomó en cuenta respecto a la construcción social de los roles genéricos de los participantes fueron los juegos; una de las formas de socialización más presente en etapas tempranas del ser humano está enmarcada por el juego; por medio de éste, las niñas y los niños reciben mensajes directos $y / o$ indirectos de las expectativas sociales que les rodean, de lo permitido, o lo prohibido según su sexo. La Campaña Latinoamericana por el Derecho a la Educación considera que:

Los juegos son importantes instrumentos de socialización, de expresión de lo lúdico y de lo artístico, de desarrollo del raciocinio lógico y cognitivo. Clarifica además que las narrativas que están presentes en los juegos son reveladoras de las relaciones sociales de un determinado contexto. (Campaña Latinoamericana por el Derecho a la Educación, 2011)

La recreación es importante para el desarrollo del ser humano, es incluso considerado como un derecho humano; los juegos y juguetes son un instrumento en la formación del género y pueden coadyuvar en la formación de una persona que respeta, que no violenta, que cuestiona, y que estimula la conviencia en equidad o bien puede conllevar los efectos contrarios, es decir, pueden ser un estimulante de la discriminación, del abuso, de la violencia y de la inequidad, es decir reproducir desigualdad social. Es común que sin tener una intención manifiesta, los adultos propiciemos un juego cualquiera y aparentemente inofensivo como "propio" o "exclusivo" de niña o de niño y seamos propulsores de inequidades de género; los juegos sexistas influyen definitivamente en la conformación identitaria y genérica de una persona:

Juegos sexistas son juegos que fortalecen estereotipos de género, muchas veces en detrimento del sexo femenino. A las jóvenes y mujeres se les reservan los juegos 
cuyo desafío es seleccionar ropas, objetos y accesorios para ellas o para el hogar o, en el caso de juegos de acción, los desafíos son conquistar al príncipe, cambiar el máximo de bebés posible o llegar puntual al casamiento. En cambio, los juegos de niños estimulan el raciocinio, tienen más diversidad, son juegos en los que el jugador tiene que perseguir algo y son más agresivos y violentos. (Campaña Latinoamericana por el Derecho a la Educación, 2011).

Sobre este tema, los participantes respondieron a la pregunta de inicio: ¿Puedes platicarme si en la infancia realizabas juegos considerados propios de niña o niño? Y profundizaron sobre su percepción cuando se les plantearon estas otras preguntas: ¿Te gustaba hacerlo? ¿Te hubiera gustado jugar a algo distinto?

Se encontró que en términos generales se les permitía jugar lo que era esperado en función de su sexo:

Yo jugaba a la mamá, a la maestra,... a la mujer maravilla. (Olga, comunicación personal, 8 de septiembre de 2009).

Jugaba mucho con mi hermano al futbol, a los cochecitos. (Carlos, comunicación personal 20 de julio de 2009).

A la mayoría se les prohibía determinantemente hacerlo con juguetes considerados para el sexo contrario. "Compórtate bien, esos juegos no son para ti, son para niños, te vas a hacer machorra".

¡Ay, te hubiera gustado ser hombre para andar jugando al futbol como tú quisieras!. (Elena, comunicación personal 20 de mayo de 2009).

Mi mamá nos decía 'ustedes no deben de jugar a juegos de niños', entonces ya no jugábamos eso. (Olga, comunicación personal 8 de septiembre de 2009).

Se aprecia la tristeza en su rostro, su voz cambia, su mirada baja; es claro el desacuerdo que muestran al recordar. En la expresión de Elena se pueden distinguir tres elementos: uno es el comportarse bien como un patrón de conducta a seguir, lo que se tiene que hacer, lo esperado; otro es la amenaza sobre el convertirse en algo indeseable, negado, es decir, en hacerse "machorra", lo cual lleva implícito un mensaje lesbofóbico; el último es la decisión negada. En la brevedad de las palabras de Olga se deja ver una especie de "rendición" ante la prohibición. 
Por otro lado, a dos de los participantes se les permitía jugar con juegos considerados para el otro sexo, aunque con la limitante de dejarlo de hacer si alguien externo a la familia nuclear observaba:

Me preguntaba por qué cuando llegaban las amigas de mi hermana a jugar ya no podía jugar a las muñecas con ellas. (Víctor, comunicación personal, 17 de septiembre de 2009).

De chiquito, a veces yo tenía ganas de jugar con muñecas o a los castillitos y mis primos, mis primitas y mis papás me decían: '¿pero, por qué juegas con muñecas?'. (Adán, comunicación personal 13 de mayo de 2009).

En ambos se aprecia la frustración al no poder jugar con lo que quisieran, y por otro lado puedo percibir el cuestionamiento de uno y otro; es decir, para Víctor como niño, era confuso el hecho de que jugar a las muñecas se limitase a quien lo observa, en privado es permitido, en público cambia a prohibido. En el caso de Adán el cuestionamiento es de los adultos -sus padres- hacia él, hay incomprensión hacia su inclinación por jugar con muñecas; esto remite a las palabras de Silvia Marcos (2011) respecto a la naturalización del género, en donde acentúa que es importante conocer las formas en que la construcción social y cultural de las relaciones de género permite, a través de la socialización que los mandatos sociales sean internalizados y considerados naturales. La madre y el padre de Adán como partícipes de una sociedad que atiende a roles estereotipados de género no escapan a sus mandatos, y parecieran pensar que el hecho de que su hijo sea varón le determinará la preferencia o rechazo a jugar con ciertos juguetes.

También existe la presencia de dos elementos importantes, la naturalidad presentada y el deseo, es decir, a pesar de que se les presentaban los juegos como lo naturalmente correspondiente a su género, existía el deseo de jugar a lo que jugaba el contrario:

Era algo muy natural, los niños juegan algo y las niñas a otras cosas... yo decía: 'ah, las casas de muñecas están padrísimas, quiero una'; y es algo extraño; ¿por qué no disfrutar de esos detallitos?" (Carlos, comunicación personal, 20 de julio de 2009). Yo no era de andar corriendo todo el recreo... cuando los ves jugar se te antoja, pero no haces nada porque ves que juegan nada más los niños y aunque me llamara la atención no hacía nada por involucrarme en eso". (Elena, comunicación personal, 20 de mayo de 2009). 
Carlos coloca nuevamente la naturalización del género, Elena mejor no hacía nada. Al igual que en la rendición de Olga, parece ser que las entonces niñas claudicaron y terminaron por aceptar lo establecido. También noté una ligera tendencia en las mujeres a percibir los juegos de niños como más divertidos:

Yo decía, ¡no es justo! ¿Por qué nos dejan lo más aburrido?. (Ana, comunicación personal, 13 de mayo de 2009).

El coartar la libertad del juego promueve la inequidad, pero sobre todo, traza una línea divisoria y desigual entre los dos sexos.

Por medio del siguiente cuadro, se nombran algunos de los juegos de la infancia y el posible mensaje transmitido:

\begin{tabular}{|c|c|}
\hline Juegos para niñas & Posible mensaje transmitido \\
\hline A la mamá & La maternidad como destino. \\
\hline Muñecas & Cuidar. \\
\hline Barbies & $\begin{array}{l}\text { Estereotipo de belleza occidental (delgada, } \\
\text { rubia, rica). }\end{array}$ \\
\hline A la comidita, hornear pasteles, juego de té & Cocinar, atender, servir. \\
\hline A la maestra & Educar, cuidar. \\
\hline Juegos para niños & Posible mensaje transmitido \\
\hline Fútbol & Jugar al aire libre, competición \\
\hline Coches & Manejo y control de situaciones, desplazamiento. \\
\hline En la calle & Libertad, desplazamiento. \\
\hline Trepar árboles & Atreverse a enfrentar retos. \\
\hline
\end{tabular}

Los resultados presentados están relacionados con lo que se afirma en otras investigaciones similares,

Atendiendo al estilo de juego como uno de los aspectos más importantes en el desarrollo del niño/a, los estudios llevados a cabo, indican que el tipo de juego que los padres realizan con sus hijos es mucho más activo y con más respuestas de control y disciplina mientras que el que realizan con sus hijas, tiende a ser más pasivo, más dependiente del adulto y con un elevado componente verbal". (Caldera en Mosteiro, 1989:244).

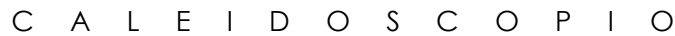


Lo cual puede significar una invitación a repensar qué tanta satisfacción hay en las niñas y los niños con quienes interactuamos respecto a los juguetes y juegos con los que juegan, y si el mensaje que se les transmite abona a una sociedad igualitaria, o estamos propiciando el efecto contrario; de igual manera, me parece que valdría la pena preguntarnos qué tan libres son al elegir sus juegos o en qué medida son imposiciones en las que no tienen mucha opción y qué tan dispuestos estamos como adultos a permitir su libre elección.

\section{REFLEXIONES FINALES}

El resultado de este trabajo tiene sustentos que desde la teoría de género permitieron acercarse a jóvenes universitarios como participantes que se involucraron y que brindaron la oportunidad de observar cómo transitaron entre distintos aprendizajes en tanto seres no determinados y en construcción permanente; la metodología cualitativa facilitó acomodar los resultados de manera meramente interpretativa y objetiva.

El tema de los roles genéricos fue significativo, puesto que resaltó los cambios presentados en los participantes tomando en cuenta el punto de partida sobre el que se les educó en su círculo primario de socialización y el lugar en el que se encontraban al momento del taller e inclusive en las propias entrevistas. No se tienen elementos contundentes para afirmar que la mirada crítica en este grupo de estudiantes se amplió a partir de cursar el taller, pero sí se puede afirmar que tuvieron elementos teórico prácticos que propiciaron ver la realidad de manera más crítica y propositiva. Teniendo en cuenta que los cambios sociales son lentos y paulatinos fue interesante apreciar que aquello que les molestó en su edad temprana, hoy lo puedan nombrar como injusto, lejos de la realidad o aburrido. Las modificaciones no sólo quedaron a nivel de un rechazo verbal, sino que se cambiaron actitudes; en este sentido, pudieron irse modificando acciones que les parecían inequitativas en favor de prácticas equitativas, como Víctor, quien en la entrevista compartió que él no iría a más fiestas hasta que dejaran a su hermana llegar a la misma hora que a él; o Carlos, quien hipotéticamente dijo que si su hijo quisiese vestirse de rosa él lo dejaría hacerlo.

Aunque todas las familias estudiadas son nucleares y en la mayoría persisten papeles de género tradicionales, se observaron marcadas 
diferencias entre ellas; en las familias nucleares tradicionales, las mujeres eran quienes realizaban las labores domésticas y pasaban más tiempo en la casa; los hombres se dedicaban a tareas que tienen que ver con la fuerza física y con los automóviles. La autoridad se atribuía al padre y la balanza de la comunicación se inclinaba hacia la madre; hay un mínimo de cambios que se han impulsado desde las hijas en mayor medida y de los hijos varones en menor medida. Las que se denominaron como familias nucleares flexibles se caracterizan por fluctuar entre roles de género estrictos y relajados; el padre y la madre participaban en labores domésticas, la comunicación parecía ser más fluida, ambos cónyuges trabajaban o habían trabajado en algún momento, lo que podría ser un factor de influencia para que los papeles de género se adaptasen a las necesidades familiares; en la familia monoparental la cabeza es el padre de familia, no se aprecian papeles genéricos rígidos; las tareas domésticas circulaban en un vaivén que atendía más a las necesidades de horario de escuela y trabajo de quienes la integran, y que no presupone el género para su desempeño.

Respecto a los juegos, la infancia de los participantes estuvo caracterizada por el deseo de jugar, y carecía de total importancia si el juego estaba destinado a un género u otro; los juegos considerados para "el otro" les llamaban la atención, les parecían divertidos e interesantes. Este deseo parecía no importar -o pasaba desapercibido- para las personas adultas que les rodeaban, ya que en mayor o menor grado existían prohibiciones y/o limitantes a jugar a aquello que les "desviara" de su papel de género; igualmente "el qué dirán" era una razón de peso que se acompañaba de una permisividad oculta, o dicho de otra manera, mientras nadie más viera que estaban jugando a lo que no les correspondía, se toleraba. También se notó que a ambos géneros les molestaba la negativa, pero dentro de esta inconformidad había quien repelaba y había quien se conformaba y a regañadientes no cuestionaba más.

El hecho de que los juegos considerados de niñas sean realizados al interior de la casa, y los de niños fuera de ella, mutila la posibilidad de una convivencia de igual a igual en el plano social y cotidiano, al caso viene recordar expresiones como "mujer de la calle", que se usa en forma despectiva, denigrante y discriminatoria para calificar a la mujer que sale de su ámbito, de lo que le toca, de la expectativa social, es decir que esté en su casa, dándole incluso una cualidad, la de ser una "mujer de su casa", o, "buena mujer"; pero el problema no para 
en la mera expresión, lo preocupante es que la naturalidad presentada en este tipo de concepciones permea las esferas de lo privado y de lo público, y se manifiesta en la cotidianeidad de hombres y mujeres recortándola de forma desigual, generando violencia, desigualdad e injusticia social.

Este grupo se formó desde su círculo primario de socialización con roles genéricos tradicionales; sin embargo, no permaneció ahí, se movió y transitó hacia el rechazo de la perpetuación de dichos roles, ya fuese porque se vieran afectados en su propia persona o porque se solidarizaran a rechazar aquello que les parecía injusto. Es decir, si bien se les transmitió la rigidez de papeles genéricos y aunque no siempre fueron conscientes del sexismo presente en los mandatos de género, esto no fue determinante para que optaran, y como jóvenes, pudiesen responder y verbalizar su rechazo de manera más contundente y clara; ahora toman distancia de ello y se separan de actitudes que desde su propia voz no van da acuerdo ni a estos tiempos, ni a lo que desean para sus propias vidas.

En estas líneas no pretende presentarse una conclusión contundente ni definitiva; pero es posible compartir pensamientos y sentimientos; el haber tenido la oportunidad de aproximación a una parte de quienes fueron partícipes de esta experiencia abrió un arcoíris de posibilidades para seguir explorando, conociendo, investigando. Los estudios de género se asientan sobre un terreno en constante movimiento que sorprende, en el que continuamente se abren nuevas interrogantes, avances teóricos y prácticos que cuestionan, ponen en duda lo anterior y retan a la continuación del trabajo, a la búsqueda permanente; ese dinamismo invita a la constante retórica, a la dialéctica, a la polémica; esto quedó claro cuando los mismos participantes dudaban, se autocorregían, disentían, consentían -y cuando de manera personal se estuvo haciendo a lo largo de esta investigación.

Si se pudieran resumir en pocas palabras sus expresiones, se diría que hubo un acuerdo común: el rechazo hacia el sistema patriarcal, cuya estructura mina la posibilidad de un mundo igualitario para los seres humanos como tales. Personalmente y después de revisar, leer, preguntar e indagar, acerca de la percepción que los nueve participantes tienen respecto a la equidad de género y cómo responden ante estas situaciones, se puede decir que este grupo tuvo un avance significativo en términos de igualdad, ya que no sólo criticó desde una cómoda postura, sino que se cuestionó, propuso, se inmiscuyó, im- 
pulsó cambios; su participación fue transformadora y hoy forma parte de acciones conscientes que posibilitan salidas al sistema patriarcal y que es un eslabón en la reconstrucción de una sociedad más justa e igualitaria.

El pensamiento feminista llegó para quedarse y continúa plantando semillas de reflexión; uno de sus legados, el tema de la equidad de género, es extenso y complejo porque se mete a las vidas cotidianas, no puede mirarse a distancia. Es indispensable elevar la mirada y fijarla en un sistema que niega y desoye las necesidades no sólo de las mujeres, las que han resultado ser las más lastimadas, sino también de los hombres, de la sociedad toda. Se palpa la firme esperanza de que desaparezcan los ceñidos corsés que por años han limitado la convivencia, el reparto de recursos, de goces, de derechos; el mundo está teniendo importantes transformaciones. El sueño de que como seres humanos vivamos nuestras vidas con igualdad puede palparse y que, aunque es largo el camino por recorrer, existen voluntades, ánimos, acciones, que se encaminan hacia el mismo lado, el horizonte está ahí, se vislumbra un panorama en el que amanece.

\section{ENTREVISTAS REALIZADAS}

Ana, 13 de mayo de 2009.

Adán, 13 de mayo de 2009 .

Elena, 20 de mayo de 2009.

Miguel, 14 de junio de 2009.

Carlos, 20 de julio de 2009.

Martha, 8 de agosto de 2009.

Olga, 8 de septiembre de 2009.

Víctor, 17 de septiembre de 2009.

\section{FUENTES CONSULTADAS}

Amorós, C. (1994). Espacio público, espacio privado y definiciones ideológicas de 'lo masculino y 'lo femenino'. En Amorós, C., Feminismo: igualdad y diferencia (21-52). México: PUEG-UNAM.

Berger, Peter L. E Luckmann, T. (1986). La construcción social de la realidad. Buenos Aires: Amorrortu. 
Campaña Latinoamericana por el derecho a la educación. (2011). Juegos sexistas. Género y Educación en América Latina y El Caribe. Recuperado el 03 de mayo de 2011 de: http://www.campanaderechoeducacion.org/sam2011/ante_los_tribunales/juegos-sexistas/

De Beavoir, S. (2012). El segundo sexo. México: Debolsillo.

Fernández, G. (2006). Desigualdad de género. El papel del Instituto Municipal de la mujer. Cuadernos sobre la equidad. Ocho propuestas para León. Reflexiones sobre los problemas de nuestra ciudad, 4. Universidad Iberoamericana León.

Figueroa, J. (2001). Varones, derechos y reproducción. ¿Podemos combinar estos términos? Desacatos, 006. Distrito Federal: Centro de Investigaciones y Estudios Superiores en Antropología Social.

Freire, P. (1994). Cartas a quien pretende enseñar. México. Siglo XXI.

Lagarde, M. (1996). Género y feminismo. Desarrollo humano y democracia. México: Horas y Horas.

Lamas, M. (2008) Cuerpo: diferencia sexual y género. México: Taurus.

Maceira, L. (2008). El sueño y la práctica de sí. Pedagogía feminista, una propuesta. México: El Colegio de México.

Mead, M. (1973) [1935]. Sexo y temperamento en las sociedades primitivas. Barcelona. España. Laia.

Mesa, M. (2009). Manual de Educación para la Sostenibilidad. País Vasco: UNESCO-Etxea. [Versión electrónica]. Recuperado de: http://www. ceipaz.org/images/contenido/16_paz_seguridad_castellano.pdf.

Money, J. (1955). Hermaphroditism, gender and precocity in hyperadrenocorticism: Psychologic findings. Bulletin of the Johns Hopkins Hospital.

Mosteiro, J. (2013). Investigaciones actuales de las mujeres y del género. Los estereotipos de género y su transmisión a través del proceso de socialización. Universidad de Santiago de Compostela.

Moreno, H. (2006). Sexismo, discriminación y hostigamiento sexual en el aula: ¿cómo detectarlo, cómo combatirlo? En Curso-Taller Equidad de género en la educación Media Superior, 96-98. México: INMUJERES-SEP. Recuperado en: http://cedoc.inmujeres.gob.mx/documentos_download/100812.pdf.

Naciones Unidas, Nueva York. (2015). Objetivos de Desarrollo del Milenio Informe 2015. Recuperado en: http://www.un.org/es/millenniumgoals/ pdf/2015/mdg-report-2015_spanish.pdf.

Oakley, A. (2015). Sexo, género y sociedad. Londres: Ashgate.

Pérez, C. (2003, 17 de octubre). 50 años de voto de las mujeres. La Jornada de Oriente. Recuperado en: http://www.lajornadadeoriente.com. mx/2003/10/17/puebla/perfil.html. 
Pérez, G. (1998). Investigación cualitativa. Retos e interrogantes. Madrid: La Muralla.

Romero, L. (2015). Percepción de estudiantes universitarios respecto a la equidad de género. Tesis de Maestría. México: Universidad de La Salle Bajío.

Rubin, G. (1975). The Traffic in Women: Notes on the Political Economy of Sex. En Reiter, R. (Ed.). Toward and Anthropology of Women (157-210). New York: Monthly Review Press.

Serbia, J. (2007). Diseño, muestreo y análisis en la investigación cualitativa. Universidad Nacional de Lomas de Zamora. Recuperado en: http:// dspace.utalca.cl/bitstream/1950/9421/1/Serbia_JM.pdf.

UNICEF. (2003). Nuevas formas de familia. Perspectivas nacionales e internacionales. Uruguay UNICEF-UDELAR.

Wagner, C. (2004). Lenguaje y género. Documentos lingüísticos y literarios, Chile: Universidad Austral. Recuperado en: www.humanidades.uach.cl/documentos_linguisticos/document.php?id=58.

Sitios en internet

Razones de Ser. (2010). http://www.razonesdeser.com/.

Semillas, A.C. (2010). http://www.semillas.org.mx.

Inmujeres. (2016) 
ANEXO 1

\section{FORMATO DE ENTREVISTA}

FECHA:

ENTREVISTADORA:

ENTREVISTADO(A):

HORA DE INICIO/TÉRMINO

GUÍA DE PREGUNTAS PARA EL TEMA DE FAMILIAS Y JUEGOS:

1. ¿En tu casa, se siguen papeles considerados culturalmente como masculinos o femeninos?

2. ¿Cuáles?

3. ¿Qué opinas al respecto?

4. ¿Puedes platicarme si en la infancia realizabas juegos considerados culturalmente como de niña o de niño?

5. ¿Te gustaba hacerlo?

6. ¿Te hubiera gustado jugar a algo distinto?

7. ¿En tu casa, se siguen papeles considerados socialmente como típicamente masculinos o femeninos?

8. ¿Como cuáles?

9. ¿Algo más que desees agregar? 